\title{
Effect of Bromocriptine on Insulin Resistance in Patients with PCO
}

\author{
Zivar Shirinpour, Bahman Ghaderian*, Homeira Rashidi, Armaghan Moravej Aleali, \\ Seyed Peyman Payami \\ Health Research Institute, Diabetes Research Center, Ahvaz Jundishapur University of Medical Sciences, \\ Ahvaz, Iran \\ Email: zshirinpour@yahoo.com, ${ }^{*}$ bahmanint@yahoo.com, hrashidi2002@gmail.com, \\ armaghanaleali@yahoo.com, peyman payami1@yahoo.com
}

Received 28 September 2014; revised 22 October 2014; accepted 20 November 2014

Copyright (C) 2014 by authors and Scientific Research Publishing Inc.

This work is licensed under the Creative Commons Attribution International License (CC BY). http://creativecommons.org/licenses/by/4.0/

c) (i) Open Access

\section{Abstract}

Introduction: Poly cystic ovary (PCO) is one of the most common endocrine disorders in women. All patients with PCO are at risk of insulin resistance, IFG and diabetes. Recently, bromocriptine is used in treatment of diabetes mellitus type II to improve insulin resistance. Objective: The aim of this study is the evaluation of bromocriptine on insulin resistance in PCO people. Patients and Methods: In this single-blind controlled clinical trial with placebo, 44 patients with PCO referring to endocrinology clinic were evaluated. Inclusion criteria were BMI > $25 \mathrm{~kg} / \mathrm{m}^{2}$ and diagnosed PCO patients according to Rotterdam criteria and rule out other causes. Blood samples were obtained for FBS, Fasting Insulin, Prolactin, TSH and 17(OH)P. They divided two groups: Case group was given bromocriptine $2.5 \mathrm{mg}$ daily and placebo was given to control group. Patients were treated for 8 days and in day 9th blood sample was obtained for FBS, Fasting insulin, HOMA-IR index. Mann-Whitney method is used for mean comparison. Results: Data analysis using showed in pre diabetes range, mean changes of FBS, insulin level and IR in Groups 1 and 2 had significant differences( $P=0.004)$, but no significant different was found in $F B S<100 \mathrm{mg} / \mathrm{dl}(P=0.92)$. In group with $B M I<30 \mathrm{~kg} / \mathrm{m}^{2}$, no significant differences were found in changes in FBS $<$ insulin level and IR $\left(P=0.13,0.13\right.$, and 0.11 respectively). In group with $B M I \geq 30 \mathrm{~kg} / \mathrm{m}^{2}$, no significant differences were found in changes in insulin level and IR $(P=0.69,0.089$ respectively). Mean systolic blood pressure changes in Group 1 and 2 in FBS $>100 \mathrm{mg} / \mathrm{dl}$ with $(P=0.036)$ were significant, but no significant difference showed in mean change of diastolic blood pressure in FBS $>100 \mathrm{mg} / \mathrm{dl}(\mathrm{P}=$ 0.99). In FBS $<100 \mathrm{mg} / \mathrm{dl}$ mean changes in systolic and diastolic blood pressures were not significant $(P=0.6)$. Age showed no difference changes in effect on treatment in Groups 1 and $2(P=0.1)$. Conclusion: Our study showed, even in the short-term consumption, bromocriptine reduced FBS and insulin levels and insulin resistance in PCO patients with pre-diabetes range.

\footnotetext{
${ }^{*}$ Corresponding author.
}

How to cite this paper: Shirinpour, Z., Ghaderian, B., Rashidi, H., Aleali, A.M. and Payami, P.S. (2014) Effect of Bromocriptine on Insulin Resistance in Patients with PCO. Open Journal of Endocrine and Metabolic Diseases, 4, 253-257. 


\section{Keywords}

\section{Bromocriptine, Insulin Resistance, PCO, FBS}

\section{Background}

Poly cystic ovary (PCO) is one of the most common endocrine disorders in women that lead to infertility [1] [2]. The prevalence of PCO is $5 \%-10 \%$ in women in reproductive age [3]. Although its cause is familial, but in genetic studies there has not been found any specific genes or chromosomal abnormality for it [4]. After the diagnosis of PCO, screening test for lipids, fasting blood sugar(FBS), and glucose tolerance test with $75 \mathrm{~g}$ glucose powder is mandatory [5], because all patients with PCO (both obese and non-obese) are at risk of insulin resistance, IFG and diabetes [6]. The prevalence of insulin resistance in women with PCO is $50 \%-70 \%$. Incidence of diabetes in people with insulin resistance is 5 - 10 times more than normal people [7].

Since, prevalence of insulin resistance in patients with PCO is high, so its existence is a risk factor for diabetes and cardiovascular disorder. Diabetes is a major cause of mortality and morbidity around the world, so understanding of diabetes can control the disease and reduces complications [8]. Early diagnosis and treatment of insulin resistance in patients with PCO is able to reduce the incidence of diabetes and its associated risk factors such as dyslipidemia, hypertension and heart disease. Bromocriptine is a drug from D2 dopaminergic agonists. It is used for treatment of hyperprolactinemia and recently is used in treatment of diabetes mellitus type II (alone or in combination with other anti-diabetic drugs).

The drug reduced HbA1C (about 0.4\% - 0.8\% percent), triglycerides (TG), LH, and testosterone level and improved insulin resistance. Although, mechanism of action is unknown yet, but it seems the reduction in hypothalamic dopaminergic tone may be involved in reducing insulin resistance.

\section{Objective}

The aim of this study is the evaluation of bromocriptine on insulin resistant on PCO people.

\section{Patients and Methods}

In this single-blind controlled clinical trial, 44 patients with PCO were evaluated. They were referred to Golestan Hospital endocrinology clinic. Informed and written consent was obtained from each patient. Inclusion criteria were BMI $>25 \mathrm{~kg} / \mathrm{m}^{2}$ and diagnosed PCO according to Rotterdam criteria and rule out other causes.

Patients with these criteria excluded from study:

1) Diabetes

2) Hypothyroidism

3) Prolactinoma

4) Congenital Adrenal Hyperplasia

5) Breast feeding

For each patient a questioner filled up included age, BMI, blood pressure and waist to hip ratio.

They divided two groups. Case Group 1 was given bromocriptine $2.5 \mathrm{mg}$ daily made by Iran Hormone Company and placebo was given to control Group 2 made by school of pharmacy, Ahvaz Jundishapr University of medical sciences. They treated for 8 days and in day 9th, blood sample was obtained for FBS and Fasting serum insulin. HOMA-IR index and HOMA $\beta \%$ were measured according to FBS and Fasting serum insulin.

This formula:

Homeostasis Model Assessment of Insulin Resistance $=$ Fasting Glucose $(\mathrm{mmol} / \mathrm{lit}) \times$ Fasting Insulin/mu/l)/ 22.5

Homeostasis Model Assessment of $\beta$ Cell function $=20 \times$ Fasting insulin (mu/lit)/Fasting Glucose (mmol/lit) $-3.5$

Hitachi 902 is used for measuring FBS. Fasting serum insulin was measured with Elaysa 2010, Chemiluminescence method. 


\section{Statistical Analysis}

Paired t-test is used for mean comparison.

\section{Results}

Mean age $26.5 \pm 5.8$ years in Group 1 and $31.3 \pm 5.8$ in Group 2. All participants had hirsutism. Twenty six patients had hirsutism associated with menstrual irregularity, 7 patients had hirsutism with sonographic changes and 11 persons had all 3 Rotterdam criteria. Only 1 of the patients had a history of hypothyroidism that TSH test was under control. All patients had abdominal obesity. From all study subjects, 22 persons had BMI 25 - 29.9 $\mathrm{kg} / \mathrm{m}^{2}, 13$ persons $30-34.99 \mathrm{~kg} / \mathrm{m}^{2}$ and 9 persons had BMI $\geq 35 \mathrm{~kg} / \mathrm{m}^{2}$. Fasting blood sugar (FBS) of 11 people was in pre diabetes range (100 - $125 \mathrm{mg} / \mathrm{dl}), 5$ patients were in Group 1 and 6 in Group 2. In total study population, 13 patients had insulin levels above normal (>16/5), 9 people were randomly assigned in Group 1 and 4 were in Group 2. Twenty eight patients initially had high insulin resistance (>2/3), 18 patients were in Group 1 and 10 patients in Group 2.

After receiving the medications in Group 1, 13 persons had decrement in FBS, 5 patients in the pre-diabetes range (100 - $125 \mathrm{mg} / \mathrm{dl})$. That all 5 (100\%) were in pre-diabetes range (100 - $125 \mathrm{mg} / \mathrm{dl})$ before study. In the placebo group, 9 patients had a decrease in FBS, 2 (33\%) of them were in pre-diabetes range before study. In Group 1, 13 patients had reduction in insulin after taking medication. 6 people had high insulin level. In Group 2, 7 patients had reduction insulin level, 2 of them had high insulin level above normal. In this study, 24 patients with interventions had decrement in insulin resistance (IR), 15 in Group 1 and 9 in Group 2. Eighteen people had high IR (>2.3) from the beginning, 12 patients in Group 1 and 6 in Group 2. In people with decrement in IR, 6 people were in pre-diabetes range $(100-125 \mathrm{mg} / \mathrm{dl})$. All of these people had IR > 2.3, 5 of them have been in Group 1 and 1 in Group 2. 9 people who had reduction in IR, had insulin level higher than normal range, 8 were in Group 1 and 1 in Group 2. In people who have reduced IR, 11 of them were overweight 7 were obese and 6 very obese. After treatment in Group 1, 8 people had reduction in BMI, 3 were overweight 1 obese and 4 very obese. In Group 2, 5 had decrement in BMI. 3 were very obese and 2 overweight. In Group 1, 11 patients had decreased systolic blood pressure and 7 diastolic blood pressures whereas in Group 2, 5 patients had decreased systolic blood pressure and 4 diastolic blood pressures.

In Table 1, the mean effects of the drug and placebo were compared in both groups before and after treatment. Data analysis using Mann-Whitney showed in pre diabetes range, mean change of FBS, insulin level and IR in Groups 1 and 2 had significant difference $(\mathrm{P}=0.004)$. But no significant different was found in FBS $>100$ $\mathrm{mg} / \mathrm{dl}(\mathrm{P}=0.92)$. In Group with BMI $<30 \mathrm{~kg} / \mathrm{m}^{2}$, no significant differences were found in changes in FBS $<$ insulin level and IR ( $P=0.13,0.13$, and 0.11 respectively). In Group with BMI $\geq 30 \mathrm{~kg} / \mathrm{m}^{2}$, no significant differences were found in changes in insulin level and IR $(P=0.69,0.089$ respectively). Age showed no difference changes in effect on treatment in Groups 1 and $2(\mathrm{P}=0.01)$. Mean systolic blood pressure changes in Groups 1 and 2 in FBS $>100 \mathrm{mg} / \mathrm{dl}$ with $(\mathrm{P}=0.036)$ were significant, but no significant difference showed in mean changes of diastolic blood pressure in FBS $>100 \mathrm{mg} / \mathrm{dl}(\mathrm{P}=0.99)$. In FBS $<100 \mathrm{mg} / \mathrm{dl}$ mean changes in systolic and diastolic blood pressure was not significant $(\mathrm{P}=0.6)$.

Table 1. Effect of treatment in case and control group.

\begin{tabular}{ccccc}
\hline \multirow{2}{*}{ Variable } & \multicolumn{3}{c}{ Before } & \multicolumn{2}{c}{ After } & P-Value \\
\cline { 2 - 5 } & Case & Control & Case & $30.08 \pm 3.23$ \\
BMI & $33.32 \pm 8.4$ & $30.6 \pm 3.27$ & $33.28 \pm 8.34$ & $68.6 \pm 5.6$ \\
DBP & $72.27 \pm 7.5$ & $70.45 \pm 4.85$ & $72.54 \pm 7.6$ & $117.27 \pm 10.7$ \\
SBP & $16.6 \pm 10.39$ & $119.1 \pm 11.9$ & $112.9 \pm 9.12$ & $96 \pm 12.5$ \\
FBS & $99.27 \pm 37.5$ & $95.22 \pm 14.9$ & $96.4 \pm 28.5$ & 0.51 \\
HOMA-IR & $4.6 \pm 3$ & $3.7 \pm 4.8$ & $4.3 \pm 3.4$ & 0.33 \\
Insulin & $19.4 \pm 12.06$ & $16.5 \pm 21.66$ & $18.53 \pm 14.2$ & $16.75 \pm 23.2$
\end{tabular}

BMI: Body Mass Index. SBP: Systolic Blood Pressure. DBP: Diastolic Blood Pressure. 


\section{Discussion}

The results show that this drug is effective in patients that had FBS in pre-diabetes range (100 - $125 \mathrm{mg} / \mathrm{dl})$ and did not affect on normal FBS. It is also has some effects on decrease of insulin level and insulin resistance. The reason is the presence of insulin resistance in pre diabetes range and mechanism of bromocriptine on insulin resistance. Bromocriptine inhibits sympathetic tone in CNS and reduce blood glucose after meals (due to suppression of hepatic glucose production). The Hypodopaminergic hypothalamic disorders are associated with the development of insulin resistance, obesity and diabetes. These results are similar to Kok study [9] [10]. Kok studied 18 obese women without PCO and BMI from 30.1 - 40.5 for 8 days. The results showed D2 dopaminergic receptor activation improved metabolic disorders include blood glucose disorder in PCO people. In Kok study, it did not show FBS range that treatment was effective. But our study showed the effects of medication on FBS in pre-diabetes range insulin level and insulin resistance. Difference between the results of our study and Kok, may be in Kok study, the PCO people have not been evaluated and study method was cross, however, our conclusion and difference with Kok study requires more evaluation [9] [10].

In the present study which is similar to Kok study, a significant reduction in systolic blood pressure was observed. In both study drug on diastolic blood pressure was not effective. Reduction in systolic blood pressure is due to dopamine D2 receptor. Because autonomic nervous system has a vital role in controlling blood pressure, and excessive sympathetic activation in obese people may increase blood pressure. Consumption of bromocriptine decrease blood pressure with block Alpha-adrenergic receptors [9]. Reduction of insulin resistance in our study had significant differences which are similar to previous studies, including Kok, Das Santos-Silva [11] Davis [12] and Lin Jia [13]. Results indicate effect of bromocriptine on insulin resistance.

In addition, in this study found that most people with PCO had high level of IR that is similar to Bahceci [14] and and Pasquql [15]. As mentioned in the pathogenesis of PCO, in addition to environmental factors such as obesity, genetic factors involve as well [9] [10]. In our study, it was found the drug had no effect on BMI like previous studies [11]. The difference between this study and our study was it has been a long-term treatment (6 months), but that our study was the short-term (8 days). While the drug's effect on body weight required at least 6 months.

Davis studies have found that bromocriptine reduces food intake and body fat and eventually reduce the sensitivity of the dopaminergic system in obese subjects. But this time of their study was 4 weeks and $10 \mathrm{mg}$ daily dose of bromocriptine was used. Whereas in our study the daily dose of bromocriptine was $2 / 5 \mathrm{mg}$ for 8 days [12]. We also found IR reduction was seen in overweight people. The random selection of patients, small sample size, may be the reason.

In the present study, for reducing of drug side effects, we advised people take medication at sleep time. But in Holt [16] they showed taking drug in the morning can improve IR and other metabolic disorders due to central effect on hypothalamus. But in our study despite taking medicine at night, mean changes in blood glucose and insulin, and insulin resistance, in both groups had significant difference.

Limitations of the present study were small sample size and short duration of drug use. The effectiveness of this drug on people with pre-diabetes needs a full comprehensive study with larger sample size.

\section{Conclusion}

Our study showed, even in the short-term consumption, bromocriptine (eight days) reduced FBS and insulin levels and insulin resistance in PCO patients with pre-diabetes range. At the same time, its ability to reduce systolic blood pressure in overweight people is more effective than obese people.

\section{Acknowledgements}

This paper is issued from thesis of Dr. Z. Shirinpour (Reg. No. 938/DF). This thesis was registered in Health Research Institute, Diabetes Research Center. Financial support was provided by Vice Chancellor for Research, Ahvaz Jundishapur University of Medical Sciences. Authors would like to thank all staff of diabetes research center Miss Dehghan and Hardani for their help in this study.

\section{Competing Interests}

The authors declare that they have no competing interests. 


\section{Authors' Contributions}

B. Ghaderian and H. Rashidi designed the study. Z. Shirinpour collected the data and wrote the manuscript. P. Payami collected data and edited manuscript. A. Aleali has done all searches, final edition and submission the manuscript. All authors read and approved the final manuscript. Thanks all authors for their support and help in this study.

\section{Financial Disclosure}

Health Research Institute, Diabetes Research Center, Vice Chancellor for Research, Ahvaz Jundishapur University of Medical Sciences.

\section{References}

[1] Hull, M.G.R. (1987) Epidemiology of Infertility and Polycystic Ovarian Disease: Endocrinological and Demographic Studies. Gynecological Endocrinology, 1, 235-245. http://dx.doi.org/10.3109/09513598709023610

[2] Dunaif, A. (1997) Insulin Resistance and the Polycystic Ovary Syndrome: Mechanism and Implication for Pathogenesis. Endocrine Reviews, 18, 774-800.

[3] Naderi, T., Akbarzadeh, M., Dabbaghmanesh, M.H. and Tabatabaei, H.R. (2012) Prevalence of Various Phenotypes of Polycystic Ovarian Syndrome among High School Girls of Shiraz (2009). The Journal of Qazvin University of Medical Sciences, 15, 60-67. (In Persian)

[4] Shivaprasad, C. and Kalra, S. (2011) Bromocriptin in Type 2 Diabetes Mellitus. Indian Journal of Endocrinology and Metabolism, 15, S17-S24.

[5] Ehrmann, D.A., Liljenquist, D.R., Kasza, K., Azziz, R., Legro, R.S., Ghazzi, M.N., and for the PCOS/Troglitazone Study Group (2006) Prevalence and Predictors of the Metabolic Syndrome in Women with Polycystic Ovary Syndrome. The Journal of Clinical Endocrinology \& Metabolism, 91, 48-53. http://dx.doi.org/10.1210/jc.2005-1329

[6] Ovalle, F. and Azziz, R. (2002) Insulin Resistance, Polycystic Ovary Syndrome, and Type 2 Diabetes Mellitus. Fertility and Sterility, 77, 1095-1105. http://dx.doi.org/10.1016/S0015-0282(02)03111-4

[7] Petersen, K.F. and Shulman, G.I. (2006) Etiology of Insulin Resistance. The American Journal of Medicine, 119, S10S16. http://dx.doi.org/10.1016/j.amjmed.2006.01.009

[8] Legro, R.S., Castracane, V.D. and Kauffman, R.P. (2004) Detecting Insulin Resistance in Polycystic Ovary Syndrome: Purposes and Pitfalls. Obstetrical \& Gynecological Survey, 59, 141-154. http://dx.doi.org/10.1097/01.OGX.0000109523.25076.E2

[9] Defronzo, R.A. (2011) Bromocriptine: A Sympatholytic, D2-Dopamine Agonist for the Treatment of Type 2 Diabetes. Diabetes Care, 34, 789-794. http://dx.doi.org/10.2337/dc11-0064

[10] Kok, P., Roelfsema, F., Frölich, M., Van Pelt, J., Stokkel, M.P., Meinders, A.E. and Pijl, H. (2006) Activation of Dopamine D2 Receptors Simultaneously Ameliorates Various Metabolic Features of Obese Women. American Journal of Physiology_Endocrinology and Metabolism, 291, E1038-E1043. http://dx.doi.org/10.1152/ajpendo.00567.2005

[11] Dos Santos Silva, C.M., Barbosa, F.R., Lima, G.A., Warszawski, L., Fontes, R., Domingues, R.C. and Gadelha, M.R. (2011) BMI and Metabolic Profile in Patients with Prolactinoma before and after Treatment with Dopamine Agonists. Obesity (Silver Spring), 19, 800-805. http://dx.doi.org/10.1038/oby.2010.150

[12] Davis, L.M., Michaelides, M., Cheskin, L.J., Moran, T.H., Aja, S., Watkins, P.A., et al. (2009) Bromocriptine Administration Reduces Hyperphagia and Adiposity and Differentially Affects Dopamine D2 Receptor and Transporter Binding in Leptin-Receptor-Deficient Zucker Rats and Rats with Diet-Induced Obesity. Neuroendocrinology, 89, 152162. http://dx.doi.org/10.1159/000170586

[13] Lin, J., Lin, G.N., Pan, J.Q., Kuang, S.S., Huang, X., Rao, Z.L., et al. (2010) Studies of Bromocriptine on Insulin Resistance and Oxidative Stress in Rats with Polycystic Ovary Syndrome and Metabolic Syndrome. Clinical Medicine \& Engineering, 12, 1-6.

[14] Bahceci, M., Tuzcu, A., Bahceci, S. and Tuzcu, S. (2003) Is Hyperprolactinemia Associated with Insulin Resistance in Non-Obese Patients with Polycystic Ovary Syndrome? Journal of Endocrinological Investigation, 26, 655-659.

[15] Pasquali, R., Casimirri, F., Venturoli, S., Paradisi, R., Mattioli, L., Capelli, M., Melchionda, N. and Labò, G. (1983) Insulin Resistance in Patients with Polycystic Ovaries: Its Relationship to Body Weight and Androgen Levels. Acta Endocrinologica (Copenhagen), 104, 110-116.

[16] Holt, R.I., Barnett, A.H. and Bailey, C.J. (2010) Bromocriptine: Old Drug, New Formulation and New Indication. Diabetes, Obesity and Metabolism, 12, 1048-1057. http://dx.doi.org/10.1111/j.1463-1326.2010.01304.x 
Scientific Research Publishing (SCIRP) is one of the largest Open Access journal publishers. It is currently publishing more than 200 open access, online, peer-reviewed journals covering a wide range of academic disciplines. SCIRP serves the worldwide academic communities and contributes to the progress and application of science with its publication.

Other selected journals from SCIRP are listed as below. Submit your manuscript to us via either submit@scirp.org or Online Submission Portal.
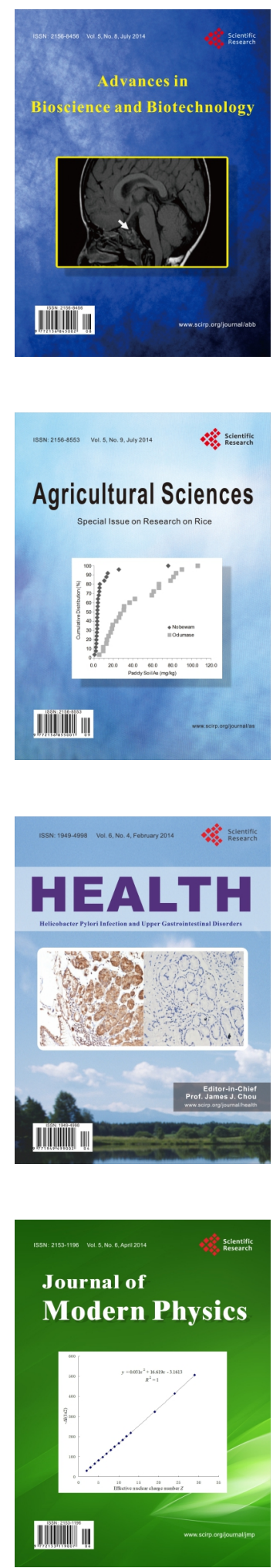
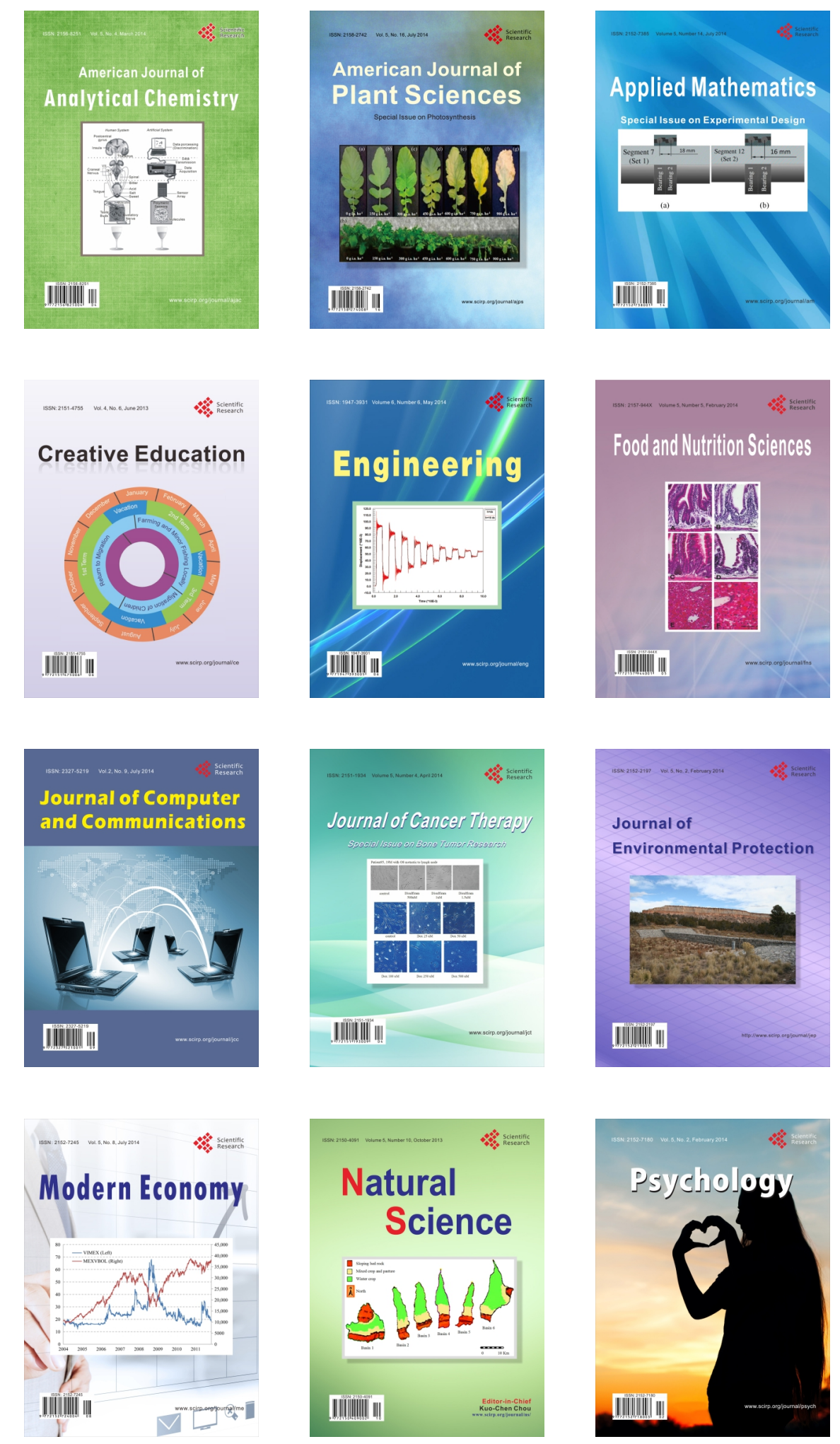